\title{
CONCEPÇÕES ACERCA DA HISTÓRIA E EPISTEMOLOGIA DA BIOLOGIA APRESENTADAS EM UMA COMUNIDADE DE PRÁTICA
}

\author{
Murilo Del Bianco Lima ${ }^{1}$ \\ Maria Júlia Corazza² \\ Lourdes Aparecida Della Justina ${ }^{3}$
}

\begin{abstract}
RESUMO
A Biologia se constituiu como uma ciência do conhecimento, passando por períodos de descrédito, nos quais não era considerada uma ciência segmentada em várias áreas de mesmo nível de reconhecimento da Física e da Química. Tais contextos acabaram influenciando a construção da disciplina Biologia, que se caracteriza como fragmentada, descritiva e memorística. A presente pesquisa, de natureza qualitativa, buscou investigar as concepções acerca da epistemologia da Biologia elucidadas por participantes de uma Comunidade de Prática, constituída por professores pesquisadores, pós-graduandos, graduandos e professores da educação básica. Os discursos dos sujeitos da pesquisa foram obtidos por meio de gravações das reuniões referentes aos temas da epistemologia da ciência, posteriormente transcritos e tratados com o auxílio da Análise Textual Discursiva. O tratamento dos dados pela ATD possibilitou a emergência de duas categorias - Biologia ou Ciências Biológicas e Biologia: construção histórica e autonomia -, que possibilitaram a construção de um metatexto sobre a natureza da Ciência Biologia. Na visão dos participantes, a Biologia caracteriza-se como uma ciência autônoma no presente momento, porém ainda não se encontra completamente unificada.
\end{abstract}

Palavras-chave: Epistemologia da biologia. Comunidade de prática. Ensino de biologia.

\section{CONCEPTIONS CONCERNING THE HISTORY AND EPISTEMOLOGY OF THE BIOLOGY PRESENTED IN A COMMUNITY OF PRACTICE.}

\begin{abstract}
Biology was constituted as a science of the knowledge, going by distrusting periods in which it was not considered a segmented in several areas of same level of recognition of the Physics and the Chemistry. Such contexts ended up influencing the construction of Biology as a subject, which is characterized as fragmented, descriptive and memorizable. This qualitative research was dedicated to investigate the conceptions about the epistemology of Biology elucidated by participants of a Community of Practice, constituted by research professors, graduate and undergraduate students and teachers of the basic education. The research speeches were obtained through recordings of the meetings regarding the themes of the epistemology of the science, afterwards transcribed and managed with the support of the Discursive Textual Analysis. The treatment of the data using DTA provided the emergence of two categories - Biology or Biological Sciences and Biology: historical construction and autonomy -, provided the preparation of a metatext on the structure of the Biological Sciences. In the participants' point of view, Biology is currently characterized as an autonomous science, however it hasn't been completely consolidated. Keywords: Epistemology of biology. Practice community. Teaching of biology.
\end{abstract}

RECEBIDO EM: 21/7/2018

ACEITO EM: 27/9/2018

\footnotetext{
${ }^{1}$ Tem experiência na área de Biologia Geral, com ênfase na prática de ensino em biologia e ciências. http://buscatextual.cnpq.br/buscatextual/visualizacv.do?id=K4366793H6. Orcid: https://orcid.org/0000-0002-7623-6816. murilobiancouem@gmail.com

${ }^{2}$ http://buscatextual.cnpq.br/buscatextual/visualizacv.do?id=K4703637P6. Orcid: https://orcid.org/0000-0001-5527-9932. mjcorazza@ gmail.com

${ }^{3}$ Licenciada em Ciências Biológicas pela Universidade Federal de Santa Maria (1998). Mestre em Educação pela Universidade Federal de Santa Catarina (2001). Doutora em Educação para a Ciência pela Universidade Estadual Paulista Júlio de Mesquita Filho (2011). É uma das líderes do Grupo de Pesquisa em Educação em Ciências e Biologia. Professora da Universidade Estadual do Oeste do Paraná, atuando na área de Educação em Ciências, principalmente nos seguintes temas: avaliação nos processos de ensino e aprendizagem, formação de professores e história e epistemologia do conhecimento científico. http://buscatextual.cnpq.br/buscatextual/visualizacv.do?id=K4701645Z2. Orcid: https://orcid.org/0000-0001-6013-7234. lourdesjustina@gmail.com
} 
Apesar de suas divergências sobre o modo de compreender a construção do conhecimento científico ao longo dos diferentes períodos históricos, tem se tornado consenso entre os epistemólogos que o desenvolvimento de cada ciência apresenta peculiaridades filosóficas. Em outras palavras, cada ciência possui sua epistemologia, apresentando objetos de estudo, problemas, métodos e outras características que lhes são próprias e lhes conferem especificidade e autonomia (ANDRADE et al., 2008). Essas características passaram a ser traduzidas pela literatura da área de pesquisa em Educação em Ciência das duas últimas décadas pela expressão "Natureza da Ciência" (DURBANO, 2012). Nesse aspecto, o termo "Natureza da Ciência" "tem sido usado para referir-se não a ciência em sentido amplo, mas, mais especificamente, às características do conhecimento científico e ao modo pelo qual ele é produzido" (GROTZER; MILLER; LINCOLN, 2012, p. 14).

Em relação a sua epistemologia, a Biologia distingue-se das outras ciências naturais pela sua constituição tardia, pelo desenvolvimento segmentado em vários campos de investigação sobre o mundo vivo, pela forte influência da Física e da Química, assim como pela luta para a autonomia e a unificação das ciências biológicas por meio da evolução. Como argumenta El-Hani (2002), o desenvolvimento histórico da ciência Biologia afetou também o modo como o currículo e o ensino das disciplinas científicas têm sido organizados e desenvolvidos nos cursos de Licenciatura em Ciências Biológicas e nas escolas de Educação Básica. Tradicionalmente, essas disciplinas têm sido reconhecidas pela sua natureza enciclopédica, fragmentada e reducionista, não sendo capazes de suscitar nos alunos uma compreensão integral e holística dos fenômenos biológicos. Isto acontece porque, tal como ocorria com a ciência de referência no início do século 20 , a falta de unidade, observada até nos dias de hoje, "em áreas como genética, citologia, zoologia, botânica, entre outras, faz com que os conteúdos sejam apresentados muitas vezes como se estivessem separados na natureza" (MEGLHIORATTI, 2009, p. 56).

Em um momento histórico, no qual a ciência deixou de ser assunto exclusivo da academia para fazer parte da vida das pessoas, em geral reivindica-se que a escola promova uma educação científica por meio da qual o conhecimento construído passe a fazer parte da cultura pessoal dos indivíduos, permitindo-lhes compreender e atuar com racionalidade na realidade em que vivem (RIVERO; WAMBA, 2011). Para que a sociedade seja capaz de obter um pensamento crítico relacionado a temas científicos, no entanto, é necessário que conheça não apenas os conceitos, mas também o que é ciência, os problemas que desencadearam os estudos, seus métodos, os resultados esperados e as consequências de suas aplicações. Várias investigações realizadas nos últimos 30 anos, tanto no âmbito nacional quanto internacional, todavia, têm demonstrado que a concepção de ciência que temos na escola é equivocada e totalmente distante dos debates epistemológicos atuais, fato que tem instigado propostas para a inserção da história e da filosofia no ensino de ciências (GIL PÉREZ et al., 2001; CACHAPUZ; PRAIA; JORGE, 2004; RIVERO; WAMBA, 2011).

Ao defender a introdução da História e Filosofia da Ciência no ensino, Biscaino e Camargo (2012) argumentam que tais tópicos não devem substituir o ensino dos conteúdos específicos de cada ciência, mas devem complementá-lo de forma a permitir a elaboração de relações entre ciência, tecnologia e sociedade. Em síntese, para Rivera 
e Wamba (2011, p. 10), o desenvolvimento de uma cultura científica requer uma formação "em ciência e sobre ciência" e esta, por sua vez, exige "mudanças profundas no ensino das ciências, desde a educação infantil até a formação de professores, e em outros âmbitos" (tradução nossa). Pautando-se nessa linha de pensamento, Andrade et al. (2008) também consideram fundamental a introdução de temas que tratam da epistemologia da Biologia nos cursos de formação de professores desta área, justificando que sua carência pode dificultar a compreensão do conhecimento biológico ao acarretar distorções conceituais que podem interferir no ensino da disciplina de Biologia.

Na perspectiva de suprir a carência de conteúdos sobre a Natureza da Ciência nos cursos de Ciências Biológicas, temas referentes à epistemologia da Biologia têm sido abordados e discutidos em uma Comunidade de Prática (CoP), cujo interesse e preocupação estão voltados para a formação inicial e continuada de professores desta área.

Essa CoP, nomeada de Comunidade de Prática em Biologia: ensino e pesquisa (CoP-Bio), foi constituída no ano de 2016, promovendo a interação entre os participantes de dois grupos de estudos e pesquisa, já existentes na época, sendo um vinculado ao Programa de Pós-Graduação em Educação para a Ciência e a Matemática (PCM) da Universidade Estadual de Maringá (UEM), e o outro ao Programa de Educação da Universidade Estadual do Oeste do Paraná (Unioeste), campus Cascavel. Nesse ano de 2016, a CoP atuou de modo presencial nos dois polos e de modo on-line, por meio de correio eletrônico, whatsApp e rede social.

O termo CoP, introduzido por Lave e Wenger no início da década de 90, passou a ser compreendido como grupos de pessoas que, ao compartilharem interesses, preocupações e problemas acerca de um tema ou domínio de conhecimento, interagem de modo contínuo envolvendo-se em um processo de aprendizado coletivo, com o intuito de melhorar sua prática social e profissional (WENGER; MCDERMOTT; SNYDER, 2002).

O presente artigo é fruto de uma pesquisa desenvolvida nos espaços interativos dos grupos que constituem a CoP-Bio, e teve o objetivo de investigar as concepções prévias e os significados construídos acerca da construção histórica e epistemológica da Biologia pelos participantes das reuniões presenciais de ambos os grupos. Para atingir tal objetivo, a investigação foi conduzida por questões de cunho epistemológico, como: A Biologia possui autonomia em relação às ciências Físicas e Químicas? Pode-se afirmar que hoje a Biologia se caracteriza como uma ciência unificada?

\section{A BIOLOGIA COMO CIÊNCIA: APORTE EPISTEMOLÓGICO}

Assim como qualquer atividade humana, a prática científica é influenciada por fatores socioculturais e históricos e é regida por interesses e ambições. Por se tratar de uma atividade que toma tempo e dinheiro, acaba sendo orientada e guiada por forças que possuem o controle do dinheiro e do tempo (LEWONTIN, 2000). Igualmente é evidente a confiança que é depositada à ciência graças à ascensão de suas áreas e ao desenvolvimento de novas tecnologias. Ao nos voltarmos para a ciência Biologia, notamos que esta é influenciada pelos interesses e necessidades da sociedade, da mesma forma que exerce influência sobre a mesma. A Biologia adentrou no século 20 como uma ciên- 
cia subdividida em vários campos de pesquisa sobre os seres vivos, apresentando uma heterogeneidade de objetos de estudos, uma divergência de interesses, além de uma multiplicidade de métodos e técnicas de investigação.

Para que possamos compreender a origem da fragmentação das Ciências Biológicas em áreas distintas de conhecimento, faz-se necessário uma breve exposição acerca de seu desenvolvimento histórico, que se caracteriza pubescente, juvenil. O termo "Biologia" foi utilizado por Lamarck, Treviranus e Budarch no início do século 19 com o propósito de sistematizar em um campo disciplinar os conhecimentos até então produzidos acerca dos seres vivos. Os conhecimentos sobre o fenômeno vida estavam dispersos em áreas como:

[...] medicina (incluindo anatomia e fisiologia), história natural, e botânica (mais ou menos uma miscelânea). A anatomia, a dissecação do corpo humano, foi até longamente, no século XVIII, um ramo da medicina, e a botânica, da mesma forma, era praticada primariamente por médicos interessados em ervas medicinais. A história natural dos animais era estudada principalmente como uma parte da teologia natural, no intuito de apoiar o argumento de um plano (MAYR, 1998, p. 53).

Dessa forma, quando epistemólogos como Bacon, Descartes e Kant dedicaram seus estudos a acerca do desenvolvimento da ciência, a Biologia ainda não havia se caracterizado como tal, ficando à margem de tais discussões filosóficas (MAYR, 2008, 1998). Em razão de sua origem tardia, a Biologia carregou, durante muito tempo, uma natureza descritiva e teleológica, incompatível à das ciências Físicas e Químicas, sendo considerada uma ciência de "segunda classe" até meados do século 20 (LEWONTIN, 2000). Como elucida Smocovitis (1992, p. 3), "Dentro de um quadro filosófico cada vez mais positivista, a Biologia, com seus remanescentes do pensamento vitalista e metodologia não rigorosa, foi vista como que cheia de especulação" (tradução nossa).

Desde muito tempo um embate entre correntes filosóficas tem sido travado acerca dos estudos referentes à vida. Inicialmente acreditava-se que tudo que possuísse movimento teria vida; nesta visão, denominada "animismo", todas as coisas (não somente os seres vivos) seriam habitadas por um espírito que as animava, colocando-as em movimento (MARGULIS; SAGAN; 2002). Com caráter espiritual, essa visão foi superada, mas a crença de que "alguma coisa" ou a presença de um "princípio vital", que distinguia a matéria viva da matéria não viva, ainda estava presente. Tal "princípio" foi denominado de "sopro vital", dando origem à corrente filosófica chamada vitalismo. 0 vitalismo acreditava que os organismos vivos se diferenciavam da matéria inerte graças à uma força vital, que não se enquadrava nem no campo de estudos da Física nem da Química (MAYR, 1998). Em contraposição ao vitalismo, uma outra corrente filosófica trouxe uma polarização para a discussão. Esta corrente compreendia as forças da natureza e os seres vivos como um mecanismo, no qual o funcionamento era regido por leis. Segundo os pressupostos de El-Hani (2002), a corrente mecanicista, como era chamada, partia do princípio de que toda a ciência era derivada da mecânica newtoniana, e todos os seres vivos poderiam ser vistos, entendidos e explicados como máquinas. $O$ vitalismo possuía muitos princípios teleológicos, isto é, princípios que buscam fins, objetivos ou propósitos para a natureza, de modo que a filosofia teleológica considera a finalidade como o princípio explicativo fundamental, o que não agradava grande parte da comu- 
nidade científica. Esses aspectos tornaram-se embate entre correntes de pensamento favorável ao mecanicismo, também chamado de fisicalismo, graças ao status de ciência que possuía a física.

Os brinquedos de corda e as maquetes automatizadas do sistema solar sugeriram aos seus inventores que até as coisas vivas poderiam ser construídas a partir de mecanismos sem vida, molas sutis escondidas, minúsculas polias, alavancas, dentes e engrenagens invisíveis. Comparando o fluxo do sangue com um sistema hidráulico e o coração como uma bomba, o físico inglês William Harvey (1578-1647) descobriu a circulação sanguínea (MARGULIS; SAGAN, 2002, p. 20-21).

Em resumo, os seguidores da teoria mecanicista consideravam que seria possível explicar a origem e a manutenção da vida por meio das leis da física. Acreditavam que os seres vivos eram máquinas e que para conhecer o ser vivo, de modo completo, era necessário dividir suas partes e estudar a fundo cada uma delas, assim como peças de uma máquina.

Nem o mecanicismo, porém, deu conta da tamanha complexidade dos seres vivos. Conforme os estudos na ciência da vida foram ganhando corpo, as explicações mecânicas foram se tornando inapropriadas. Em sua essência, o mecanicismo não resistiu ao peso crescente dos estudos biológicos. $O$ estudo dos seres vivos tornou-se mais complexo, menos comparativo, movendo a preocupação em estabelecer relações holísticas que auxiliem na compreensão do real (JACOB, 1983). Mayr (2008) também comenta sobre a dificuldade que o pensamento fisicalista encontrou ao tentar explicar os seres vivos, quando elucida que as ciências físicas, "[...] nas quais se baseava a filosofia da ciência clássica, eram dominadas por um conjunto de ideias inadequadas ao estudo dos organismos: elas incluíam o essencialismo, o determinismo, o universalismo e o reducionismo" (p. 15).

Dessa maneira, esta corrente filosófica trouxe uma conjuntura desfavorável ao desenvolvimento da Biologia, que passou a sofrer uma forte coação reducionista às leis físicas e químicas, principalmente da mecânica newtoniana. Para se desfazer desse aspecto de ciência pejorativa, a Biologia necessitava de uma teoria com força suficiente para atribuir uma explicação acerca do mundo vivo, e, como explica Smocovitis (1992, p. 1), "Somente com a evolução, que desafiou a redução à física e à química por causa de seus elementos metafísicos, ao mesmo tempo que introduziu um agente causal mecânico para a mudança evolutiva, pode a biologia alegar autonomia" (tradução nossa).

Com o reconhecimento da teoria evolutiva de Darwin, emergiu também, no século 20, uma outra forma de pensar a Biologia, uma vez que o mecanicismo se mostrou insuficiente para a complexidade apresentada pelos seres vivos; tratava-se do desenvolvimento de ideias oriundas de correntes filosóficas intituladas organicismo e emergentismo (SMOCOVITIS, 1992).

O organicismo relaciona-se e se baseia na organização do vivo, não no organismo em si, mas na organização existente entre os vários níveis de complexidade. Para o organicismo, o que diferencia a matéria viva da matéria inanimada não seria sua composição ou ainda uma força que habita nos corpos vivos, mas, sim, o pensamento de que os seres vivos possuem diferentes níveis de organização, desde o mais simples até o mais complexo. A criação de um nível de organização propicia uma nova interação, o que vai 
ocasionar a criação de um próximo nível organizacional, e, dessa forma, aumenta cada vez mais a complexidade dos seres vivos. Jacob (1983, p. 23), quando expõe acerca da corrente organicista, esclarece que:

[...] nos seres como nas coisas, trata-se de um invisível de camadas superpostas. Não há uma organização do vivo, mas uma série de organizações encaixadas umas nas outras como bonecas russas. Atrás de cada uma esconde-se uma outra. Além de cada estrutura acessível à análise acaba se revelando uma nova estrutura, de ordem superior, que integra a primeira e the confere suas propriedades.

O fato de o organicismo ser declaradamente uma resposta ao já inadequado mecanicismo, não significa que ele compactue com os princípios vitalistas. Torna-se bastante claro que o organicismo tem alguns pontos em comum com o vitalismo, assim como com o mecanicismo, porém apresenta divergências importantes em relação a ambos. Etxeberria e Umerez (2006, p. 3), quando argumentam acerca do tema, expõem que

Confrontando um e outro, o organicismo concorda com o primeiro grau de holismo, que o leva a defender a importância de levar em consideração todo o sistema, o todo e a necessidade de diferentes níveis na explicação da organização viva, mas mantendo com o segundo a crença de que os processos vivos devem ser objeto de explicações materiais (Tradução nossa).

Isso explica o porquê de, juntamente com a ascensão do organicismo, ter-se o aparecimento de outra corrente filosófica que veio somar para a compreensão das propriedades do mundo vivo. Sendo considerada um complemento do organicismo, a corrente chamada de emergentismo possui como princípio o afloramento de propriedades novas em um determinado nível organizacional do sistema. Segundo esta corrente, várias emergências possibilitam uma nova interação, logo propiciam a criação de um nível ainda mais complexo, no qual novas emergências podem aparecer. Mayr (2008, p. 41) explica o princípio emergente como aquele que "[...] em um sistema estruturado, novas propriedades emergem em níveis mais altos de interação que não poderiam ser previstas a partir do conhecimento dos componentes em níveis inferiores". Assim, o emergentismo compartilha a ideia de que, por meio de um arranjo organizacional e complexo, possam emergir novas características, as quais interagem entre elas mesmas para formar um nível organizacional mais complexo. Dessa forma, o pensamento organicista/emergentista foi amplamente aceito como uma filosofia da Biologia, e tal aceitação teve seu impacto para a sua posição como ciência, sem precisar mais se encaixar nos moldes mecanicistas ou vitalistas. Como expõe Mayr (2008, p. 55), "A derrocada final do mecanicismo e de sua nêmese, o vitalismo, e a aceitação, no século XX, do paradigma do organicismo/emergentismo, tiveram um impacto profundo sobre a posição da biologia entre as ciências". Tal impacto é sentido na filosofia da ciência, posto que agora a Biologia tem uma forma de pensar específica e particular, tem um jeito próprio de se desenvolver; o organicismo caracteriza-se como o problema central da Biologia, e apenas para a Biologia.

Nas décadas inicias do século 20, com o afloramento do positivismo lógico pelo Círculo de Viena e com as ciências experimentais, como a genética, ganhando cada vez mais força e reconhecimento, as ciências históricas, que não eram passíveis de experimentação e observação, como a Teoria da Evolução, apenas esperavam seu fim. Eis que 
surge um grupo de biólogos da época, oriundos de diferentes áreas da Biologia, com o objetivo de matematizar a teoria evolutiva de Darwin, com a intenção de dar à seleção natural um caráter mais positivista. Dessa forma, nas décadas de 20 e 30, esse grupo de biólogos, juntamente com matemáticos, seguiu metodologias físicas e matemáticas para fazer com que a evolução conseguisse fazer parte do que era considerado ciência na época (SMOCOVITIS, 1992). A evolução, axioma principal para a Biologia, não poderia ser desacreditada de tal forma, pois esse descrédito também se refletiria no descrédito da Biologia como ciência unificada.

Com os esforços desse grupo de biólogos, foi possível tornar a seleção natural um dos agentes da evolução, quantificável. Parafraseando Smocovitis (1992), nesse momento o mecanismo causador da teoria da evolução tornou-se quantificável, e a teoria da evolução passou a ser aceita pela ciência positivista. O nascimento da genética e os reconhecidos avanços da biologia molecular, no entanto, acabaram trazendo outro reducionismo para a Biologia. Etxeberria e Umerez (2016, p. 2) explicam a forma reducionista de a biologia molecular entender a vida como "um esforço para retraduzir a maioria dos processos para sua base molecular, juntamente com o apoio na informação genética". Tal problema, isto é, a molecularização da Biologia, causou um reducionismo nesta ciência, e esta redução ocorreu porque em níveis moleculares o organismo perde sua complexidade, e os processos e reações que ocorrem podem ser, e até são, mais bem explicados com o auxílio da Química e da Física.

Os anos finais do século 20 apresentaram uma perspectiva determinista da Biologia de desvendar os segredos da vida por meio do desenvolvimento do projeto Genoma Humano. Como descrevem Etxeberria e Umerez (2006), todavia, os próprios resultados obtidos nesta empreitada científica apresentam desfechos que convergem para a oportunidade de uma "integração transformadora" das tradições biológicas. Tal oportunidade de reunir as diferentes áreas da Biologia se deve, de certa forma, à insatisfação das próprias explicações reducionistas proporcionadas pela Biologia Molecular, o que nos leva a um paradigma que emerge das cinzas do organicismo, e que se pauta em uma abordagem mais holística das práticas heterogêneas da Biologia.

\section{PERCURSO METODOLÓGICO}

A presente investigação caracteriza-se como uma pesquisa qualitativa que, segundo Moreira (2011, p. 76), está pautada em "uma interpretação dos significados atribuídos pelos sujeitos às suas ações em uma realidade socialmente construída". Neste tipo de investigação o pesquisador possui excepcional importância na constituição dos dados, posto que a pesquisa qualitativa "toma como pressuposto que a experiência humana é mediada pela interpretação, a qual não se dá de forma autônoma, mas na medida em que o indivíduo interage com o outro" (MOREIRA, 2011, p. 76). É por meio das interações entre os participantes da pesquisa, incluindo os autores desta investigação, portanto, que são construídas as interpretações, trazendo a visão de mundo encontrada tanto no pesquisador quanto no sujeito pesquisado.

Dada a importância do contexto e das interações dinâmicas para a pesquisa qualitativa, ressalta-se que a presente investigação se constituiu como participante, na qual o pesquisador fica imerso no ambiente de pesquisa (MOREIRA, 2011). Neste caso em 
específico, além de fazerem parte, de modo ativo, na realidade do grupo, os pesquisadores também participaram das interações dialógicas realizadas dentro do contexto de pesquisa. A pesquisa participante foi desenvolvida historicamente como uma forma de negação da pesquisa de cunho positivista, como modalidade satisfatória. Parafraseando a autora Teresa Maria Frota Haguette (1990), elencamos alguns princípios a que a pluralidade da pesquisa participativa submete-se. Ao realizar uma pesquisa participante, 0 observador se faz presente no ambiente investigado, além de compartilhar das atividades e contextos do grupo, e ainda se colocar no lugar do outro, para que seja possível atribuir sentidos em suas ações e discursos.

A pesquisa iniciou no ano de 2016 e teve como sujeitos os participantes da CoP-Bio, constituída nesse mesmo ano. Como já explicado, essa CoP é formada por dois grupos de estudos e pesquisa ligados a programas de Pós-Graduação de duas diferentes Instituições de Ensino Superior (IES) do Estado do Paraná. Constituem a CoP-Bio, um grupo ligado ao Programa de Pós-Graduação em Educação para a Ciência e a Matemática (PCM) da Universidade Estadual de Maringá (UEM), e outro vinculado ao Programa de Educação da Universidade do Oeste do Paraná (PPGE ?? Unioeste/campus Cascavel). Durante o ano de desenvolvimento da pesquisa, a CoP-Bio apresentou uma certa fluidez tanto na composição quanto no número de seus membros, isto porque, em razão de motivos diversos, alguns deixaram de frequentar as reuniões enquanto outros integraram-se aos grupos no decorrer do período. Além disso, em virtude da não obrigatoriedade da frequência, um número variável de participantes pode ser observado nos encontros presenciais de ambos os grupos durante o período. Por questões éticas o nome dos participantes não foi divulgado e, para identificá-los, utilizamos siglas, que foram atribuídas de acordo com a atividade que realizavam. Desse modo, aos professores do Ensino Superior foi atribuída a sigla PS; aos pós-graduandos do curso de Mestrado em Educação ou Educação para a Ciência, a sigla PGM; os acadêmicos do curso de Doutorado foram designados de PGD; aos professores da Educação Básica foi conferida a sigla PB; e para alunos de Graduação a letra G. Alguns participantes possuíam mais de uma atividade, apresentando ambas as siglas. É o caso do participante PBPGM1, que, no período, era acadêmico de Mestrado e também atuava como professor da Educação Básica.

Durante o ano de 2016 foram trabalhados diversos temas na CoP-Bio, e essa pesquisa abrange dados das discussões da quarta temática, referente ao processo de constituição, autonomia e unificação da Biologia.

Para construir os dados, as reuniões referentes ao tema foram gravadas e, posteriormente, transcritas fielmente, sem modificações dos discursos. Após sua constituição, os dados foram tratados por meio da Análise Textual Discursiva, metodologia descrita por Moraes e Galiazzi (2014), e pautada em três momentos ou etapas denominadas de: unitarização/desconstrução, categorização e síntese de um metatexto. Após intensas leituras, o pesquisador realizou a primeira etapa: o processo de desconstrução ou unitarização do texto do "corpus". Esta etapa "consiste num processo de desmontagem ou desintegração dos textos, destacando seus elementos constituintes", ou seja, "Da desconstrução dos textos surgem as unidades de análise, aqui também denominadas unidades de significado ou de sentido" (MORAES; GALIAZZI, 2014, p. 18). 
O processo de categorização pode ser realizado utilizando-se categorias construídas dos referencias teóricos da pesquisa, chamadas de dedutivas. Nesta pesquisa as categorias foram construídas a partir das unidades de análise, sendo nominadas categorias indutivas, construídas "Por um processo de comparar e contrastar constante entre as unidades de análise", durante o qual "o pesquisador vai organizando conjuntos de elementos semelhantes, geralmente com base em seu conhecimento tácito" (MORAES; GALIAZZI, 2014, p. 24).

Em seguida, iniciamos um processo de reestabelecimento da ordem, ou seja, o que incialmente foi desconstruído para que seus reais valores pudessem emergir, foi novamente organizado na construção de um metatexto, que tem o objetivo de captar e comunicar o novo emergente. Neste tipo de análise os metatextos são construídos a partir da unitarização e categorização, sendo importante salientar que estes "não devem ser entendidos como modos de expressar algo já existente nos textos, mas como construções do pesquisador com intenso envolvimento de sua parte" (MORAES; GALIAZZI, 2014, p. 39).

Nesta pesquisa foram identificadas duas categorias - Biologia ou Ciências Biológicas e Biologia: construção histórica e autonomia -, que convergiram para a produção de um metatexto que será apresentado e discutido no próximo item.

\section{O METATEXTO: \\ a ciência biologia: da construção à autonomia e unificação}

As discussões referentes aos dados que constituíram esta pesquisa, realizadas nos dois grupos presenciais que constituem a CoP-Biologia, voltaram-se para os conhecimentos históricos e epistemológicos desta ciência. Mais precisamente, incluíram diálogos acerca da constituição histórica da Biologia como a ciência do mundo vivo no século 19, e dos esforços empreendidos, nas primeiras décadas do século 20 , na busca de sua autonomia e unificação. Os dados, obtidos das transcrições desses encontros e submetidos à ATD, deram origem a três categorias finais de análises, utilizadas na composição deste metatexto: a fragmentação presente na Biologia; sua autonomia e unificação; e a evolução como elo articulador das diversas áreas de pesquisa da Biologia.

As discussões epistemológicas, cujos dados constituíram a primeira categoria de análise - a fragmentação presente na Biologia -, tiveram início no grupo presencial da Unioeste - Cascavel - quando PS4, professora pesquisadora e uma das mediadoras desse grupo de estudos e pesquisa, colocou a seguinte questão para reflexão:

Então pessoal, a química a gente chama de química mesmo, por que que a Biologia a gente chama de Ciências Biológicas? (PS4 - Unioeste).

Os participantes demonstraram uma certa insegurança em suas respostas, como podemos observar no seguinte fragmento de discurso:

Isso é uma coisa que quando eu li o texto falei: nossa...! nunca tinha me dado conta que as pessoas falam Ciências Biológicas e outras usam Biologia, né? Aí eu fiquei, assim, muito intrigada com isso. Que estranho né. Por que a gente não chama de Ciências Biológicas na escola. É Biologia (PGM4 - Unioeste). 
Ao explorar o discurso anterior, percebemos concepções prévias que ressaltam a ausência de discussões de âmbito epistemológico na formação dos sujeitos. Isso reflete um descaso dos biólogos com as questões acerca da construção da Biologia, como já explicitado por Mayr (2008), ao considerar que a maioria dos biólogos desprende poucos esforços para a compreensão da história e da filosofia da Biologia. No grupo fixado na UEM, um início para os debates epistemológicos foi possibilitado pelo questionamento de PS1, professora pesquisadora e uma das mediadoras da CoP-Bio, e que também levou tal questão para o grupo da Unioeste/Cascavel:

Vocês preferem o termo "Biologia" ou "Ciências Biológicas" para denominar nossa ciência? (PS1 - UEM, Unioeste).

De início percebemos, em ambos os grupos, que a indagação da professora PS1 possibilitou uma reflexão dos participantes em relação ao processo de construção dessa ciência. Embora apresentando certa insegurança em sua resposta, o participante PBPGM3 (UEM) relacionou o termo Biologia à matéria escolar e Ciências Biológicas ao processo histórico de como os conhecimentos biológicos foram construídos.

Eu creio que Biologia seja a matéria escolar, né? E Ciências Biológicas é. compreenderem os conhecimentos biológicos ... como eles foram construídos (PBPGM3-UEM).

Ao associar o termo Ciências Biológicos ao processo histórico da construção do conhecimento sobre o mundo vivo, esse pós-graduando, provavelmente, não esteja querendo afirmar que desde os seus primórdios os vários campos de investigação da Biologia já eram reunidos sob essa denominação, mas pode estar implícito neste discurso uma relação semelhante à realizada por Smocovitis (1992) ao atrelar o termo à tentativa de um "casamento forçado" dos vários campos do conhecimento biológico, constituídos de forma desunida e não articulada desde a Antiguidade até o final do século 19 pelos naturalistas das décadas inicias do século 20. Por outro lado, ao associar o termo Biologia à matéria escolar, PBPGM3 também não deixa claro se está expressando uma forma de pensamento tal como a de Selles e Ferreira (2005), ao relatarem que esse termo substituiu, em 1960, as denominações das disciplinas escolares Ciências Naturais e História Natural, empregadas até aquele momento histórico. Como explicam as autoras, a substituição dos nomes das disciplinas por Biologia teve o intuito de demonstrar a unificação das desarticuladas Ciências Biológicas em meados do século 20.

Ao dar andamento às reuniões do grupo da Unioeste/Cascavel, notamos a emergência do termo fragmentação, inicialmente acompanhado de contextos, sentidos e significados desarmoniosos em relação à construção epistemológica da Biologia, como podemos confirmar nos discursos:

\section{É da fragmentação em Ciências Biológicas? (PGM7 - Unioeste).}

Ciências Biológicas seria o estudo de forma fragmentada... assim como a gente faz aqui... a gente não estuda de forma interdisciplinar (G3 - Unioeste).

Nota-se que houve um rearranjo de ideias com a apropriação do termo fragmentação, o qual emergiu, inicialmente, por integrantes que já haviam interagido com as questões epistemológicas em foco. Damiani (2008, p. 216), ao se pautar nas ideias de 
Vygotsky, argumenta que em uma CoP é frequente o processo de imitação, responsável pela internalização, "processo que se distingue da cópia porque implica em uma reconstrução interna de operações externas, na qual o sujeito desempenha um papel ativo e tem possibilidades de desenvolver algo novo". Orientando-se em Bakhtin, a autora elucida que as pessoas desenvolvem um processo de "ventriloquismo", expressando-se pelas palavras dos outros para que depois tais palavras possam ser utilizadas adequando-se aos seus sentidos e vontades.

Nos encontros seguintes da CoP-Bio, que trataram das discussões sobre a construção histórica da Biologia, constatamos que os termos desunião ou fragmentação são retomados nos diálogos proferidos em ambos os grupos presenciais:

Várias ciências que em conjunto formaram esse tópico, né? Ciências Biológicas... então já dá um caráter de subdivisão (PBPGM3 - UEM).

Os fragmentos, né?... uma ciência fragmentada... de guarda-chuva. (PGD2 - UEM).

O termo umbrealla (guarda-chuva) foi utilizado por Smocovitis (1992, p. 2), em seu artigo Unifying Biology: The Evolutionary Synthesis and Evolutionary Biology, ao se referir às primeiras organizações da Ciência Biologia, caracterizadas pela simples junção dos diversos campos do conhecimento biológico, sem uma devida articulação entre eles. Segundo a autora, esse tipo de organização, baseada em práticas heterogêneas, manteve-se praticamente intacta até o início da década de 50 , durante a qual presenciou-se grandes transformações na organização dessa ciência. Vale ressaltar que nesses encontros da CoP-Bio notamos a interação não apenas entre os participantes, mas também entre eles e os textos de apoio, trabalhados com o objetivo de possibilitar a aprendizagem docente e a construção de significados. Ao utilizar um termo empregado por Smocovitis (1992), a participante PGD2 apropria-se da palavra, atribuindo, primeiramente, sentidos à imagem mental para depois elaborar significados por meio das interações interpessoais. Para Vygotsky (1993) e Vigotski (2001), o significado da palavra é, ao mesmo tempo, um fenômeno do discurso como também do pensamento, podendo ser considerado um sinônimo de generalização ou conceito, cuja elaboração somente se torna possível pela interação social.

Retornando às discussões epistemológicas, pode-se considerar que a própria construção histórica da Biologia, da forma como foi realizada, constitui-se na principal causa da sua fragmentação em Ciências Biológicas. Além de se caracterizar como uma ciência desunida, a Biologia não apresentava o mesmo status quo da Física e da Química, de modo que, desde o final do século 19, tem sido empreendida uma luta para conseguir sua autonomia e unificação. Os dados obtidos das discussões desses dois processos na CoP deram origem a segunda categoria de análise - autonomia e unificação da Biologia.

O termo autonomia pode ser motivo de algumas confusões quando usado como sinônimo de independência. A autonomia que a Biologia busca, todavia, está longe de ser entendida como total ausência de dependência ou interação com os conhecimentos produzidos em outras ciências, questão que os participantes de ambos os grupos buscaram esclarecer ao serem indagados pela professora mediadora PS1: 
Autonomia está mais relacionada com individualidade ou um estilo próprio (PGD2 - UEM).

É diferente de falar que ela é independente (PGM6 - Unioeste).

Então..., as questões que são lançadas são diferentes... elas têm, assim... elas instigam uma forma diferente, mesmo, de pensar nessa construção do conhecimento biológico (PGD2 - UEM).

Eu acho que (autonomia) seria mais assim... as características que nos permitem estudar o mundo vivo (PGM6 - Unioeste).

Em conformidade com os discursos dos participantes, Etxeberria e Umerez (2006) elucidam que o termo autonomia deve ser entendido no contexto da epistemologia da Biologia como uma forma de emancipação ou de autogoverno, um meio de caminhar com os próprios métodos. Ter uma autonomia é possuir questões próprias e particulares, uma forma única de pensar seu conhecimento, uma epistemologia voltada para a construção de seus saberes; é possuir uma metodologia. Questionados acerca da autonomia da Biologia na atualidade, após as leituras, os participantes são unânimes em concordar com Mayr (2008, p. 55), que expõe que "a Biologia não só tem todos os atributos necessários de uma ciência genuína como também difere da física em aspectos importantes, de modo que deve ser considerada uma ciência autônoma". Sobre sua autonomia, vale ressaltar que, em razão de seu surgimento tardio, a Biologia não estava presente nas discussões epistemológicas dos séculos 16, 17 e 18, as quais consideravam a Física um modelo de cientificidade a ser seguido, como afirmam os participantes do grupo presencial da UEM:

Na epistemologia quem foi a pioneira? A Física... ela vai gerar traços porque nasceu dentro disso sabe... vai ter traços... A nossa epistemologia (da Biologia), querendo ou não... ela nasce dentro da epistemologia da Física (PBPGM2 - UEM).

Tal discurso demonstra uma complexa organização mental ao elucidar que a Biologia não se enquadrava no que a epistemologia da ciência considerava no momento como imagem, uma vez que, além de se diferenciar em relação às características do seu objeto de estudo, de sua metodologia, da sua história, também apresenta uma filosofia distinta das demais ciências naturais. Percebemos, ainda, por meio do seu discurso, que o participante apresenta conhecimento de que a filosofia da Biologia é juvenil, surgindo em meados do século 20, como asseveram Flach e Del Pino (2016). Em virtude deste fato, os filósofos da ciência prevaleceram por muitos séculos sob a influência da filosofia da Física, utilizando-a para explicar a ciência da vida.

Quando colocados no ambiente interativo da CoP, discursos semelhantes aos de PBPGM2 contribuem para a negociação de significados entre os membros, possibilitando que alguns que se encontram no nível periférico da CoP, como os novatos, que acompanham com frequência as reuniões, mas não interagem diretamente nas discussões, passem para o nível ativo, constituído por sujeitos que se envolvem diretamente nos estudos, discussões e outras atividades da comunidade (WENGER; McDERMOTT; SNYDER, 2002). Deste modo, como explica Damiani (2008, p. 217), os participantes de uma CoP "atingem significados e representações comuns, possivelmente mais complexos e ricos do que aqueles elaborados individualmente". 
Nos últimos encontros referentes ao tema autonomia e unificação da Biologia, após leituras e discussões, os participantes trouxeram falas acerca da compreensão da teoria sintética da evolução como elo articulador das diversas áreas de conhecimento biológico. Vale ressaltar que estas falas estão apresentadas inicialmente nas características que a evolução necessitou adquirir para ser considerada uma teoria de força o bastante para ser capaz de unificar a Biologia.

A discussão era que a evolução seria apropriada para inter-relacionar todas as áreas das Ciências Biológicas... é: Mas pra isso, não aquela evolução como ela estava descrita até o início do século, porque ela era muito metafísica... O que que precisou fazer pra evolução para ela ser aceita como ciência? (PBPGM3 - UEM).

Ter experimentação... ter no caso observação... as leis, né? As leis da evolução (PGD2 - UEM).

Os arquitetos né: da nova síntese evolucionista, eles queriam trazer dentro da evolução uma forma de estudar e de pensar a Biologia. Que assim... é: como se a Biologia estava buscando sua própria autonomia por meio desse carácter de estudo evolutivo, e também por questão dela ser agora matematizável, né: com a questão de você calcular a genética de populações e conseguir aplicar todas aquelas fórmulas matemáticas... ou seja, de trazer a Biologia para um campo experimental... Só que daí parece que também ficou muito... a Biologia era uma ciência se ela fosse atrelada à genética... não sei se vocês sentiram isso? (PGD2 - UEM).

Porque justamente a genética tinha a parte matemática maior né? (PBPGM2 UEM).

As discussões acerca dessa temática foram realizadas após leitura do artigo de Smocovitis (1992, p. 2), para a qual "Somente com a evolução, que desafiou a redução à física e à química por causa de seus elementos metafísicos, ao mesmo tempo que introduziu um agente mecânico causal para a mudança evolutiva, pode a Biologia alegar autonomia" (tradução nossa).

Nota-se nas análises interpretativas realizadas nesses enunciados de discursos precedentemente citados, que a teoria evolutiva teria a capacidade de unificar as áreas da Biologia apenas se fosse enquadrada no que o positivismo lógico pensava acerca da ciência. Após a criação da síntese evolutiva (SMOCOVITIS, 1992, p. 4), "A evolução depurada de elementos metafísicos inaceitáveis tornou-se a 'ciência central' da Biologia, que liga entre si e fundamenta as práticas heterogêneas da Biologia em uma unificada e progressiva ciência" (tradução nossa).

Pra você entender como o ser vivo é organizado, você tem que analisar a história dele que é a evolução (PGD2 - UEM).

Porque na verdade os arquitetos queriam unificar a Biologia pela evolução... como se as narrativas históricas... como se toda a história do surgimento da vida e da evolução das espécies pudesse unificar todas as outras Ciências Biológicas (PGD2 - UEM).

Seria realmente o princípio central da organização das ciências Biológicas? ...Eu acho que sim né... nada na Biologia faz sentido a não ser a luz da evolução (PBPGM1 - UEM). 
Ao finalizar os encontros referentes à construção histórica e à epistemologia da Biologia, alguns questionamentos foram refeitos com o intuito de verificar novamente as concepções acerca do tema, apresentadas pelos participantes de ambos os grupos. Ao adentrarem mais a fundo na tentativa de unificação da Biologia, os participantes elucidam, por meio dos discursos, as intenções dos arquitetos da síntese evolutiva, como no fragmento de discurso da participante PGD2 (UEM):

Os arquitetos né: da nova síntese evolucionista... eles queriam trazer dentro da evolução uma forma de estudar e de pensar a Biologia... que assim é: como se a Biologia estava buscando sua própria autonomia por meio desse caráter de estudo evolutivo e: também por questão dela ser agora matematizável (PGD2 - UEM).

Nota-se ainda nos discursos de PBPGM2 e PGM1 da UEM, a referência à genética, que, no momento da síntese evolutiva, foi a responsável por trazer o caráter experimental e calculável para a Ciência Biologia. Este fato mostra que, na verdade, a filosofia da ciência ainda se pautava no mecanicismo, fazendo-se necessário o surgimento de um ramo que utiliza a matemática em suas análises para que a Biologia pudesse ser considerada uma ciência unificada e autônoma. Em relação à unificação da Biologia, a participante mediadora PS1 refaz a indagação: "e a questão da unificação, que vocês acham?" A resposta vem de forma unânime, como demonstrado no fragmento da participante PGD2 ao argumentar "estar longe" dessa unificação se tornar concreta, como também podemos atestar com os fragmentos de discursos:

Eu acho que é uma unificação igual a "PS1" chama de forçada... ciência de guarda-chuva (PBPGM3 - UEM).

Não é a unificação que a gente quer ainda (PBPGM2 - UEM).

Lendo isso ficou claro que faltam algumas coisas para terminar de "amarrar" isso aí (PBPGM3 - UEM).

Coerente com os fragmentos da participante PGD2 e com o restante das respostas dos grupos, Jófili, Leão e Rocha (2009, p. 132) afirmam que "a Biologia continuou a ser estudada como aglomerados de partes isoladas, ora pertencentes ao macro ou ao microuniverso". Ainda para as autoras, a fragmentação enfrentada não apenas pela Biologia, mas pela ciência de modo geral, é um dos fatores que dificultam a compreensão do todo de maneira holística, causando um distanciamento do que Morin (2000) propõe como pensamento complexo.

Ao final dos encontros observamos que, em ambos os grupos, alguns dos sujeitos da CoP-Bio apresentavam uma participação mais ativa em relação aos demais, demonstrando uma maior capacidade de organização de ideias e eloquência. Atribuímos este fato a uma maior familiaridade com o tema, muitas vezes relacionada ao nível de formação acadêmica (Doutorado ou Mestrado completo, pós-graduandos de Mestrado ou Doutorado em Educação em Ciências) e ao contexto de atuação dos participantes da CoP (linhas de pesquisa).

\section{CONSIDERAÇÕES FINAIS}

O desenvolvimento desta pesquisa possibilitou que os participantes da Comunidade de Prática de Biologia: ensino e pesquisa iniciassem ou intensificassem seus estudos acerca da construção histórica e da filosofia da Biologia. As discussões motivadas pelas 
duas questões de pesquisa - A Biologia possui autonomia em relação às ciências Físicas e Químicas? Pode-se afirmar que hoje a Biologia se caracteriza como uma ciência unificada? - desencadearam importantes reflexões e compartilhamento de ideias que propiciaram a construção de significados, entre os quais destacamos:

- para os integrantes da CoP-Bio, a Biologia apresenta características que a distingue de outras ciências, como a física e a química. Tais características, ao serem somadas com a filosofia organicista/emergentista, atribuem à Biologia um caráter de ciência autônoma. É possível notar uma concordância dos sujeitos da pesquisa com Mayr (1998, 2008), ao alegarem para a Biologia um status de ciência nivelado ao da física e da química, da mesma forma que os integrantes da pesquisa compactuam com o pensamento de El-Hani (2002) ao afirmar que, mesmo com a autonomia da Biologia, não presenciamos uma independência da mesma em relação as outras ciências;

- levando em conta a concepção dos participantes em relação à unificação da Biologia, percebemos uma discordância dos mesmo com Mayr $(1998,2008)$, ao inferirem que a unificação das ciências biológicas ainda não se efetuou. Por mais que esforços tenham sido feitos no século passado, atualmente a Biologia ainda é uma ciência fragmentada. Estes discursos encontram apoio no pensamento de Selles e Ferreira (2005, p. 55), ao considerarem que uma visão unificada das Ciências Biológicas é um estereótipo, e tem fortalecido o status da Biologia unificada tanto como ciência quanto como disciplina escolar.

\section{REFERÊNCIAS}

ANDRADE, M. A. B. S.; BRANDO, F. R.; MEgLhIORATTI, F. A.; JUSTINA, L. A. D.; CALDEIRA, A. M. A. Epistemologia da Biologia: uma proposta didática para o Ensino de Biologia. In: ARAÚJO, E. S. N. N.; CALUZI, J. J.; CALDEIRA, A. M. A. (org.). Práticas integradas para o ensino de Biologia. São Paulo: Escrituras, 2008. p. 13-36.

BISCAINO, Aline Portella; CAMARGO, Sérgio. O enfoque histórico-filosófico da ciência no ensino e na formação inicial de professores de Física. SIMPÓSIO NACIONAL DE ENSINO DE CIÊNCIA E TECNOLOGIA, 3., Ponta Grossa, PR, 2012.

CACHAPUZ, António; PRAIA João; JORGE Manuela. Da educação em Ciência às orientações para o ensino das Ciências: um repensar Epistemológico. Ciência e Educação, v. 10, n. 3, p. 363-381, 2004.

DAMIANI, Magda F. Entendendo o trabalho colaborativo em educação e revelando seus benefícios. Educar, Curitiba: Editora UFPR, n. 31, p. 213-230, 2008.

DURBANO, J. P. D. M. Investigação das concepções de alunos de Ciência s Biológicas do IB/USP acerca da Natureza da Ciência. São Paulo: Instituto de BioCiências, 2012.

EL-HANI, Charbel Niño. Uma Ciência da organização viva: organicismo, emergentismo e ensino de Biologia. In: SILVA FILHO, Waldomiro et al. (org.). Epistemologia e ensino de Ciências. Salvador, BA: Arcádia, 2002. p. 199-242.

ETXEBERRIA, A.; UMEREZ, J. Organización y Organismo en la Biología Teórica ¿Vuelta al Organicismo? Ludus Vitalis, v. 14, n. 26, p. 3-38, 2006.

FLACH, P. Z. S. A.; DEL PINO. Afinal, para que servem a história e a filosofia da biologia? Educação Por Escrito, Porto Alegre, v. 7, n. 2, p. 236-252, jul./dez. 2016.

GIL PÉREZ, D.; MONTORO, I. F.; ALÍS, J. C.; CACHAPUZ, A.; PRAIA, J. Para uma imagem não deformada do trabalho científico. Ciência e Educação, vol. 7, n. 2, p. 125-153, 2001.

GROTZER, T. A.; MILLER, R. B.; LINCOLN, R. B. Perceptual, Attentional, and Cognitive Heuristics that Interact with the Nature of Sciece to Complicate Public Understanding of Science. In: KHINE, Myint S. (ed.). Advances in Nature of Science Research, 27. DOI 10.1007/978-94-007-2457-0_2, C Springer Science+Business Media B.V. 2012.

HAGUETTE, Teresa Maria Frota. Dialética, dualismo epistemológico e pesquisa empírica. In: HAGUETTE, Teresa Maria Frota (org.). Dialética hoje. Petrópolis: Vozes, 1990. 
JACOB, François. A lógica da vida: uma história da hereditariedade. Trad. Ângela Loureiro. Rio de Janeiro: Ed. Graal, 1983.

JÓFILI, Z. M. S.; LEÃO A. M. A. C.; ROCHA M. F. Biologia: ensinos possíveis e indispensáveis no novo milênio. In: SELLES, S. E.; FERREIRA, M. S.; BARZANO, M. A. L.; SILVA, E. P. Q. (org.). Ensino de Biologia: histórias, saberes e práticas formativas. Uberlândia: Edufu, 2009. p. 131-148.

LAVE, J.; WENGER, E. Situated learning: legitimate peripheral participation. 2 ed. Cambridge: Cambridge University Press, 1991.

LEWONTIN, Richard C. Biologia como ideologia: a doutrina do DNA. Tradução e revisão F. A Moura Duarte. Ribeirão Preto: Funpec-RP, 2000.

MARGULIS, Lynn; SAGAN, Dorion. O que é vida? Rio de Janeiro: Jorge Zahar Ed., 2002.

MAYR, E. Desenvolvimento do pensamento biológico: diversidade, evolução e herança. Tradução Ivo Martinazzo. Brasília: Ed. Universidade de Brasília, 1998.

MAYR, Ernest. Isto é Biologia: a Ciência do mundo vivo. Trad. Claudio Angelo. São Paulo: Companhia das Letras, 2008.

MEGLHIORATTI, Fernanda Aparecida. O conceito de organismo: uma introdução à uma epistemologia do conhecimento Biologia na formação de graduandos de Biologia. Bauru, SP: Universidade Estadual Paulista; Faculdade de Ciências, 2009.

MORAES, Roque; GALIAZZI, Maria do C. Análise textual discursiva. 2. ed. ljuí: Ed. Unijuí, 2014.

MOREIRA, Marco Antônio. Metodologias de pesquisa em ensino. São Paulo: Ed. Livraria da Física, 2011.

MORIN, Edgar. Os sete saberes necessários à educação do futuro. Tradução Catarina F. da Silva e Jeanne Sawaya. 2. ed. São Paulo: Cortez; Brasília, DF: Unesco, 2000.

RIVERO, A.; WAMBA, A. M. Naturaleza de la Ciencia y Construcción del Conocimiento Científico. La Naturaleza de la Ciência como Objetivo de Enseñanza. In: CAÑAL, P. et al. Biología y Geología. Complementos de Formación Disciplinar. Educação Secundária, v. 1, 2011.

SELLES, S. E.; FERREIRA, M. S. A. Disciplina escolar Biologia: entre a retórica unificadora e as questões sociais. In: MARANDINO, M.; SELLES, S. E.; FERREIRA, M. S. A. A. C. R. (org.). Ensino de Biologia: conhecimentos e valores em disputa. Niterói: Eduff, 2005. p. 76-81.

SMOCOVITIS, V. B. Unifying Biology: The Evolutionary Synthesis and Evolutionary Biology. Journal of the Hitory of Biology, California, 1992.

VIGOTSKI, L. S. A construção do pensamento e da linguagem. 1. ed. São Paulo: Martins Fontes, 2001. p. 496.

VYGOTSKY, L. S. Pensamiento y Lenguaje. Obras Escogidas. Tomo II. Madrid: Visor, 1993.

WENGER, E.; McDERMOTT, R.; SNYDER, W. M. Seven Principles for Cultivating Communities of Practice. 1. ed. Boston: Harvard Business School Press, 2002. 